\title{
Pleistocene preserve: a population growth problem of mammoth proportions
}

\author{
Thomas R. Beatman* and R. Joel Duff
}

\begin{abstract}
A number of processes that involve large numbers are critical to civic scientific literacy, including many biological topics. Understanding the basic causes of such large-scale processes, such as population growth, speciation, and extinction, are key to engaging evolution and ecology learning. Here we present a teaching module which uses manipulatives to addresses one such topic, population growth, utilizing charismatic organisms, mammoths. The module involves an engaging hypothetical scenario, the restoration of mammoths from extinction (de-extinction) in a captive population being grown to be placed in zoos globally. The module explores both population growth modeling and carrying capacity in relation to both modern elephant conservation and human population growth. We include detailed laboratory instructions for both students and instructors. While we designed and implemented it in a non-majors biology course, further extensions are detailed to utilize more robust modeling and complex scenarios for inquiry-driven majors biology and advanced population ecology courses. This module allows for exploration of a number of concepts within population growth, with natural lead-ins to additional topics. We make the case for mammoths and elephants more generally as charismatic organisms for which students' familiarity can leverage engagement with many important biological concepts, in this case population growth.
\end{abstract}

Keywords: Elephants, Mammoths, Population growth, De-extinction, Carrying capacity, Education, Deep time, Number literacy, Manipulatives

\section{Background}

Humans have demonstrable difficulties engaging with concepts that involve large numbers, and by extension, large scales in time and space exceeding those they encounter in their daily lives (Catley and Novick 2009). This becomes increasingly relevant when observing the challenges in engaging the public in the narratives of such biology topics as evolution, biodiversity, conservation, ecology, and population growth, where appreciating the actual scale of the numbers involved is essential (Cheek 2012; Tibell and Harms 2017). Misconceptions undermine both environmental literacy (Zimmermann 1995) and the wider understanding of scientific processes (Schoon and Boone 1998). These misconceptions are a major threat as the gap grows between current public understanding of science and the required civic scientific

*Correspondence: trb66@zips.uakron.edu

Department of Biology, University of Akron, Akron, OH 44325-3908, USA literacy needed for meaningful discourse in government science policy decisions.

At an early age, humans view relative numbers on a logarithmic scale, with the proportionate size (logarithmic scale) of different numbers being visualized rather than the absolute relative size (linear scale) (Siegler and Opfer 2003). As children age, they transition from logarithmic to linear as they become familiar with larger numbers. While this transition has been documented in adults and larger numerosities (Rips 2013; Landy et al. 2014), the majority of studies have focused on child development and smaller numerosities (Siegler et al. 2009). This in turn presents challenges, as humans are dependent on an approximate number system to gauge the relative sizes of larger numbers (above 5-7) (Hyde 2011; Nieder and Dehaene 2009); the accuracy of this system becomes increasingly unreliable at larger number scales, and is not applicable to appreciating the actual numerosities involved (Siegler and Opfer 2003; Landy et al. 2013). The 
lab presented here serves to aid students in recognizing and overcoming these hurdles.

Understanding population growth is a prominent process that involves conceptualizing large numbers. The mechanics, scale, and affecting factors in population growth are fundamental not only in environmental literacy, but also in appreciating large-scale systems including ecology, extinction, and the roles human activity, habitat loss, and climate change play in biodiversity loss and conservation efforts (Trombulak et al. 2004; Jha and Bawa 2006). Human population growth is an important concept for students to understand and grapple with, but the direct social relevance and conflicts with religious dogmas can produce problematic cognitive dissonance which can deter students from engaging with the material.

\section{Visualizing the problem: elephants and deep time}

Many commercially available population growth lab modules consist of human-focused population growth mathematics exercises with limited-to no hands-on/ experiential learning content (Smith 2010). A solution to engaging lay audiences with this population growth, while sidestepping the dissonance that can occur with a focus on humans, is to use charismatic non-human models. Elephants and their kin are used here in a teaching laboratory module focusing on using population growth to demonstrate processes which involve large scales and numerosities. The historical, temporal, and geographical ranges of proboscidean groups (see Additional file 1 for more details) across their 60 my history exquisitely illustrate a number of concepts which feature the intrinsic psychological challenges involved for biology students and lay audiences of grasping the immense scale, both in terms of space, count of individuals, and time, implicit as the result of considering these animals through deep time. Furthermore, elephants and their kin, as large, prominent, and charismatic animals (Leader-Williams and Dublin 2000) with a robust fossil record and long lifespan, can be used to explore and model scientific concepts for science communication and education settings.

In addition, the concept of de-extinction, made popular from numerous magazines articles (from such publications as Popular Science, Discover, and Science) and the Jurassic Park franchise, is incorporated to spark engagement in the classroom, and a willingness to explore the challenges and problems of population growth.

\section{Pleistocene preserve: a simulation exercise demonstrating population growth}

The pleistocene preserve laboratory module (PP) is a manipulatives-based simulation exercise designed for use in either introductory biology lab courses or in lecture settings. Taking as little as $1 \mathrm{~h}$ to complete in the form presented here, it examines multiple dynamics of population growth and their potential consequences using a hypothetical mammoth de-extinction scenario. While this lab is not about the efficacy, ethics, or plausibility of bringing back mammoths, it does touch on some of these issues incidentally and instructors can choose to explore these concepts further if they wish (see Additional file 2: Overview guide for instructors). In the configuration presented the lab addressed the following learning objectives: (A) Understand what exponential population growth is and how to identify when it is occurring; (B) understand what carrying capacity is and what conditions affect carrying capacity; (C) be able to identify factors that may limit exponential population growth; (D) understand that exponential growth is possible but not biologically realistic; (E) recognize that each species have different population growth rates; (F) connect knowledge gained from studying mammoths to issues involving human population growth and carrying capacity.

In the manipulative-based simulation, students initially determine how long it would take to grow a mammoth population from a single resurrected mating pair to a population in which every (AZA accredited) zoo in the country houses their own pair of breeding mammoths for further captive breeding and rewilding. Students engage in a hands-on exercise using manipulatives to process and calculate population growth through the use of a simple exponential growth model in a resource unlimited environment. It allows them to trace the number of mammoths at any given age interval and the number of new mammoths born in each time interval. Following 100 years of the simulation, the students can then plot the population growth, and use it to determine doubling time. They can then use this to calculate the time required to reach various population landmarks.

The simulation allows students to visualize what exponential growth is and how it works, how population doubling times can be determined from growth data, and how carrying capacities determine the limits to population size. It covers topics corresponding to NGSS HS. Interdependent Relationships in Ecosystems (HSLS2-1, HS-LS2-2, HS-LS2-6, HS-LS2-7, HS-LS2-8, and HS-LS4-6), as well as Ohio's Learning Standards B.DI.2 and ENV.ES.1. Prior to working through the simulation module, instructors may choose to use a presentation (Additional file 1) to provide students introductory questions and information relating to population growth broadly, as well as the natural history information that informs the simulation's construction. This presentation provides students with basic reproductive data for mammoths approximated from the life histories of extant species (aggregated from Loxodonta cyclotis, L. africana, 
and Elephas maximus), and then walks them through the construction and use of the simulation.

\section{Materials}

The only materials needed for this activity are enough copies of the population tracker (included in Additional file 3) that students can form groups of two to three, a means to record population sizes and growth over 100 years (the base simulation operates in 10 year intervals) and plastic counting cubes or a functional equivalent such as beads or dry beans. The countables are used to track the number of mammoths at any given age interval, and the tracker enables students to distinguish the ages of each subset of mammoth and the number of reproductively active animals.

\section{Simulation layout}

In the module, students are trying to determine how long it would take to produce enough mammoths that every zoological park in the United States would have a mating pair, followed by the world (in a simple scenario where individual zoo mammoths have reproductive access to one another). The number of zoos is an analog for total carrying capacity for the mammoth population, and allows a simple target-driven approach to thinking about growth rates.

Students use a Mammoth Age Tracker sheet (Additional file 4) to track the number of mammoths at any age, in 10-year intervals, and a supply of plastic cubes or similar manipulatives to use as counters, and a table to fill out with data. The module utilizes manipulatives to visually convey population size, with the aging and growth of the population being directly handled by students allowing a clear connection between the underlying ideas and the physical changes the simulation maps out. The Mammoth Age Tracker is split into six spaces. Each space represents a 10 year interval, with the first two spaces covering the period when they are still calves and do not reproduce. The remaining four spaces $(20,30,40$, and 50$)$ cover the rest of the mammoths' lifespan, during which they can reproduce, producing two more mammoths in every 10 year (one space) interval.

For this exercise, each cube represents two mammoths that were born over the course of 10 years (elephants give birth every 5 years, so in 10 years they can give birth to both a male and female; this is a simplified model assuming that males and females are born alternating, rather than randomly with a 50:50 distribution). The rationale for having a single cube represent a pair of mammoths is to both reduce the amount of individual manipulatives needed for the simulation, as well as to simplify the workings of mating pairs; students do not need to consider or track the sex of individual elephants. At the start of the simulation, a single cube, representing the starting pair of mammoths at the start of the simulation, is placed in the second space, to simulate the initial pair having just reached mating age, and the female in the pair about to give birth to the first of this new population of mammoths.

Students advance this cube to the next space in line, representing the passing of 10 years, during which two more elephants (represented again, by a single cube) are born and placed in the first space of the tracker. Each time you move all of the mammoths on the track, 10 years have passed, and any mammoth pair that has moved into a space on the mature portion of the track gives birth to a new pair (Fig. 1). Students can in each 10 year interval count the total number of cubes on the tracker, including those just born, and enter that number into their data table. This continues for ten 10-year intervals so students have population growth data for the first century of the simulation, which they graph out to allow them to roughly calculate the population's doubling time.

Doubling time is estimated by choosing a time point on their data curve, measuring the number of mammoths at that time, finding the intercept point of the curve for double that number, and then measuring the amount of time passed (Fig. 2). They can then use this number to roughly estimate how much time will be needed for the population to hit their target numbers (233 for AZA zoological parks, 10,000 zoos worldwide).

An additional set of questions follow, which relate the exercises to extant elephant populations, how carrying capacity can be impacted, and the major causes of issue in modern conservation efforts.

Following the end of exercises, a final series of questions highlight the relevance of carrying capacity and population growth to mammoth population size and conservation. This in turn is then leveraged to also examine how human population size and carrying capacity relate to the materials covered. The initial exercise serves as a backdoor to the impact of human populations. The role of humans in global climate change, ecosystem decline, and habitat destruction are frequently hammered into students without meaningful redress for the cognitive dissonance created. Students' personal behavior often remains unchanged due to a sense of helplessness or pointlessness in trying to affect global problems, which makes disengaging from the material the common source of dissonance relief (Festinger 1962; Cooper 2007).

\section{Extensions}

The complete PP provided only addresses population growth of a single species under optimal conditions. This enables the instructors of general education courses to draw clear conclusions with respect to the primary 


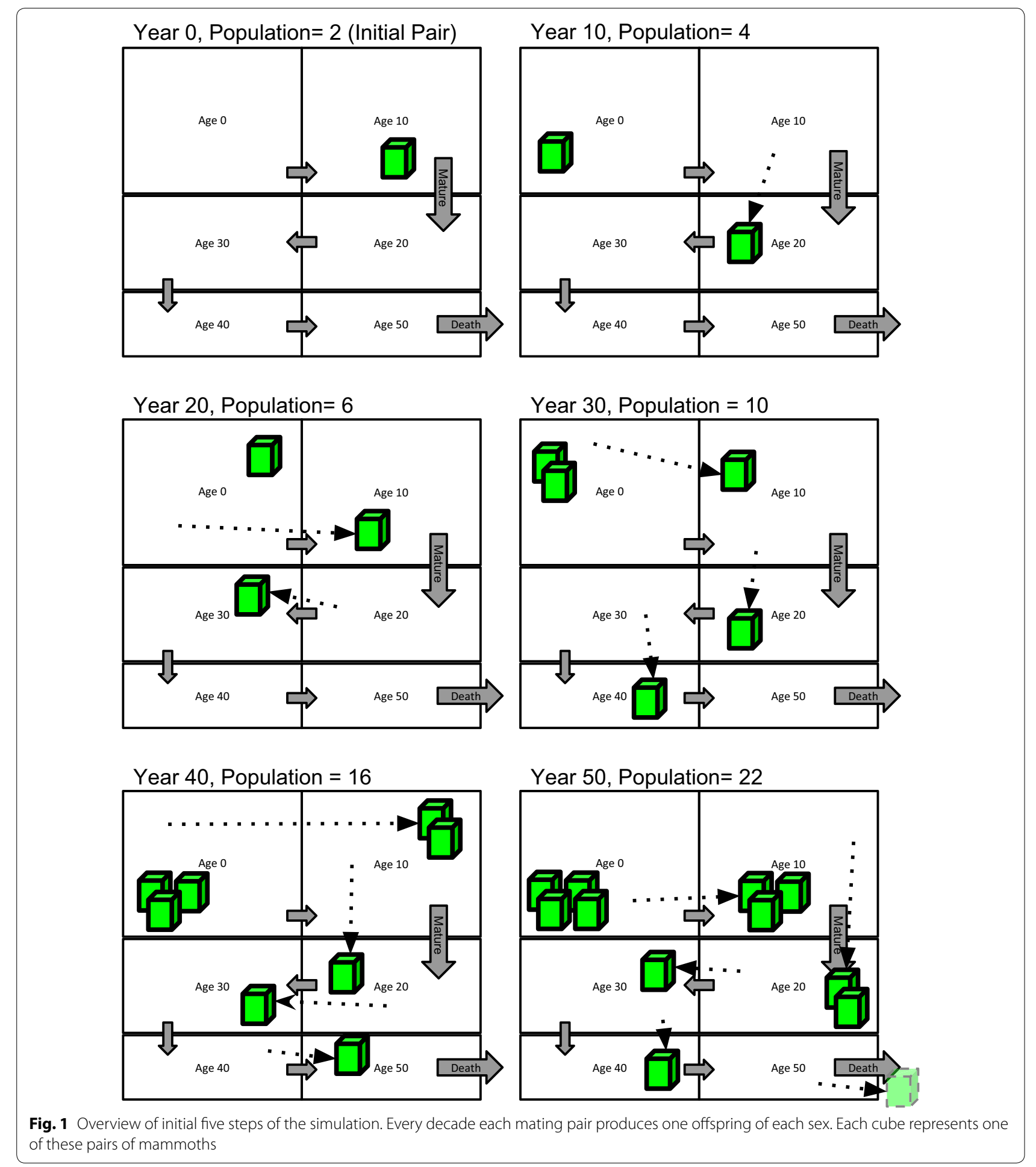

learning objectives of the PP module while also allowing students to further explore, through exercise questions what the limits of population growth are and what might change the rates of population growth. The PP exercise can be completed in $1 \mathrm{~h}$ or less making it easily accessible in a laboratory context or as a guided activity in a classroom environment. This lab can be readily extended to further explore the primary learning objectives but also to incorporate numerous additional related biological and ethical principles. 


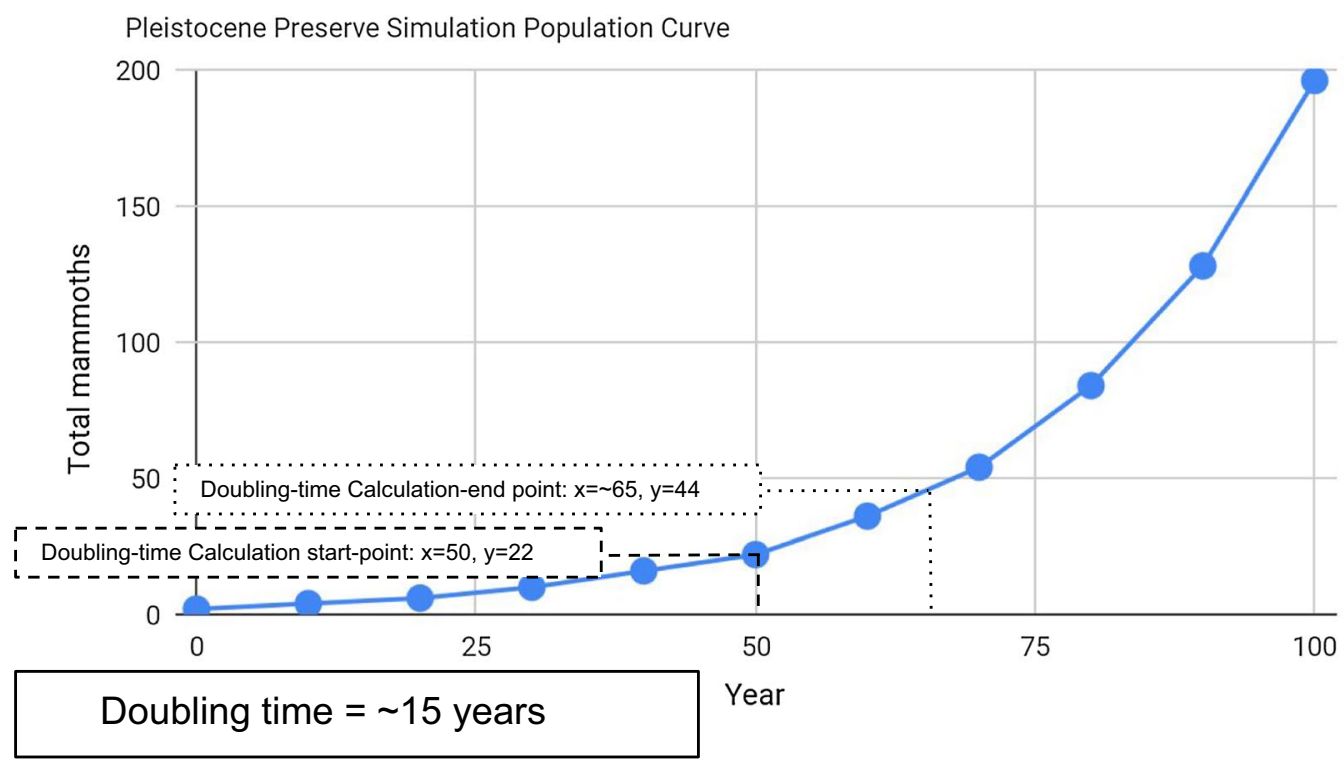

Fig. 2 Example of data collected from the PP simulation which students will use to estimate population growth. In this version, the doubling time was calculated using the 50 year time-point and population numbers to determine that in 15 years the population doubles. Student error will likely lead to variation in this number within acceptable ranges for the exercise

Faced with estimating population growth of mammoths students should wonder: How might these growth estimates compare to other organisms? Obviously fruit flies can increase in population size at a must faster rate but why and how much faster? We suggest, for advanced biology classes, running the same simulation exercise with another organism either after the mammoth simulation lab or side-by-side with the mammoth simulation. For example, this could be done with groups each performing the simulation on different species or every group could do the mammoth simulation and then could be asked to find natural history information on a second species and design a simulation that would allow them to collect data and estimate population growth rates for that other species.

We suggest using common and easily recognized organisms such as deer, dinosaurs, eagles or rabbits as examples. The population growth simulation can be altered most simply by adjusting the following parameters, (1) time to first offspring, (2) \# of offspring per female and (3) interval between offspring. In each case you assume equal numbers of male and female offspring and you track the female reproduction to estimate total population size. For example, with rabbits one could assume they reach maturity in 1 year, have six offspring (three females) per female and a lifespan of 6 years (5 reproductive years). The scorecard would be adapted by changing the intervals from 10 to 1 year and population growth would be simulated out for only 10 years of data to be able to measure the growth rate.

Each of these simulations raise interesting ecological and population biology questions because each species has different exponential growth rates. By contrasting and comparing a number of additional biological principles can be explored. The PP module simulation can be adapted to allow students to experience exponential growth and appreciate some aspect of the relationship of time and large numbers. However, experiencing ideal growth rates should help them realize that such rates are rarely sustained in the real world. Population growth rates are affected by numerous internal and external factors. The questions at the end of the lab seek to have students think through some of the possible factors that could affect growth rates; a natural extension of the PP module would be to have students actually modify the input values-the assumptions that allow ideal growth rates to occur-and run simulations which allow them to measure the effects that such changes make.

As an example, predation is an important factor that increases mortality rate and thus decreases population growth rates. A simple model of predation (not scaled with density effects) can be simulated by adding in the assumption that a fixed number of all offspring will not survive to reproductive stage. Usually in elephants, adult size protects from predation, and so subadults are most vulnerable. In our mammoth example if we assume that 
death before maturation is $20 \%$ then we would simulate this by the removal of two of every ten offspring that are produced. This can be done in a number of ways such as using a random number generator (either electronic or a 10-sided die) to screen immatures as they pass the age threshold to maturity, or simply removing the last two of every ten that pass the age threshold. Predation could also include poaching by humans. A scenario for class based on real-world data for elephants might be: if 1 of every 10 mature elephants is killed in a single time interval, how would that affect the doubling time of the elephant population?

Running the simulation again by including this variable will allow students to compare theoretical growth rates with a population growth rate that is modified by a biologically realistic variable. Questions would then include comparing those rates and how much of an effect the variable would have on populations over long periods. Many additional factors which affect mortality and birth rates can be simulated using real-world data either provided by the instructor or obtained by students from the literature.

The PP module can readily be adapted for advanced college courses using an inquiry format. Our module leads students stepwise through the process of doing the simulation but advanced students in an inquiry laboratory or classroom setting can be first presented with a question such as how long would be required to fill 500 zoos with a pair of mammoths starting with just a single sexually mature pair? Without providing them any background information or possibly only limited natural history information, individual or groups of students would then be required to construct a population growth model with the goal of allowing the students to self-discover what information they might need to produce a robust population growth model including age of reproductive maturity, senescence, death, mortality, and starting population (and others) to see how changes alter growth rates and population size. Subsequently students can be provided information to plug into their model, run the simulations, and collect data. Following the idealized simulation under optimal growth conditions, students can propose scenarios/conditions that could occur (e.g. climate change/glaciation, increased human predation, changes in life history), and then propose changes in growth conditions that would correspond with such scenarios to observe the results. This allows students to directly manipulate both hypothetical and real data (e.g. actual current elephant population sizes from recent timepoints to highlight current decline).

\section{Preliminary student assessment}

The PP module was initially utilized in an undergraduate general education biology class at The University of
Akron in the summer of 2018. The authors introduced the lab and observed and interacted with students as they participated in the laboratory exercise. The lab coordinator and teaching assistant assigned to the lab provided follow-up written feedback about student reactions to the lab. In the following fall semester changes to the lab were implemented based on the pilot lab experience, primarily streamlining and clarifying the lab instructions to allow students to complete the activity more independently.

\section{Additional files}

Additional file 1. Pre-lab PowerPoint presentation: A suggested PPT presentation to provide pertinent background information and provide an overview of the laboratory procedures. Notes are included with the slides as a guide for presenters.

Additional file 2. Overview Guide for Instructors: Additional background information useful for teaching the lab and for expanding its content.

Additional file 3. Pleistocene Preserve laboratory module for college Gen-Ed or college-prep High-school biology courses. Included are worksheets, directions and questions for students.

Additional file 4. Simulation exercise worksheet to print for students for laboratory module.

\section{Acknowledgements}

We wish to thank the students of the University of Akron's biology generaleducation course in the summer and fall of 2018 for test-driving the lab module and providing invaluable feedback. We are indebted to lab coordinator Deborah Ammerman and instructor Dr. Jennifer Peteya for their implementing the lab and providing instructional feedback.

\section{Authors' contributions}

TRB designed the activity, facilitated data collection, and wrote the manuscript. RJD participated in the development and implementation of the lab and helped to write the manuscript. All authors read and approved the final manuscript.

\section{Competing interests}

The authors declare that they have no competing interests.

Received: 8 October 2018 Accepted: 14 June 2019

Published online: 19 June 2019

\section{References}

Catley KM, Novick LR. Digging deep: exploring college students' knowledge of macroevolutionary time. J Res Sci Teach. 2009;46(3):311-32.

Cheek KA. Students' understanding of large numbers as a key factor in their understanding of geological time. Int I Sci Math Educ. 2012;10:1047-69.

Cooper J. Cognitive dissonance: 50 years of a classic theory. Thousand Oaks: Sage; 2007

Festinger L. A theory of cognitive dissonance. Redwood City: Stanford University Press; 1962

Hyde DC. Two systems of non-symbolic numerical cognition. Front Hum Neurosci. 2011;1962(5):1-8.

Jha S, Bawa KS. Population growth, human development, and deforestation in biodiversity hotspots. Conserv Biol. 2006;20(3):906-12.

Landy D, Silbert N, Goldin A. Estimating large numbers. Cogn Sci. 2013;37(5):775-99. 
Landy DH, Charlesworth A, Ottmar E. Cutting in line: discontinuities in the use of large numbers in adults. In: Proceedings of the 36th annual conference of the cognitive science society. Vol. 36. 2014. pp. 815-820.

Leader-Williams N, Dublin HT. Charismatic megafauna as "flagship species". In: Entwistle A, Dunstone N, editors. Priorities for the conservation of mammalian diversity: has the panda had its day?. Cambridge: Cambridge University Press; 2000. p. 53-81.

Nieder A, Dehaene S. Representation of number in the Brain. Annu Rev Neurosci. 2009;32(1):185-208.

Rips $\sqcup$. How many is a zillion? Sources of number distortion. J Exp Psychol Learn Mem Cogn. 2013;39(4):1257-64.

Schoon KJ, Boone WJ. Self-efficacy and alternative conceptions of science of preservice elementary teachers. Sci Educ. 1998;82(5):553-68.

Siegler RS, Opfer JE. The development of numerical estimation: evidence for multiple representations of numerical quantity. Psychol Sci. 2003;14(3):237-43.

Siegler RS, Thompson CA, Opfer JE. The logarithmic-to-linear shift: one learning sequence, many tasks, many time scales. Mind Brain Educ. 2009;3(3):143-50.
Smith GR. A module-based environmental science course for teaching ecology to non-majors. Bioscene J Coll Biol Teach. 2010;36(1):43-51.

Tibell LAE, Harms U. Biological principles and threshold concepts for understanding natural selection: implications for developing visualizations as a pedagogic tool. Sci Educ. 2017;26(7-9):953-73.

Trombulak SC, Omland KS, Robinson JA, Lusk JJ, Fleischner TL, Brown G, Domroese $M$. Principles of conservation biology: recommended guidelines for conservation literacy from the education committee of the society for conservation biology. Conserv Biol. 2004;18(5):1180-90.

Zimmermann M. Science, nonscience, and nonsense: approaching environmental literacy. Baltimore: Johns Hopkins University Press; 1995.

\section{Publisher's Note}

Springer Nature remains neutral with regard to jurisdictional claims in published maps and institutional affiliations.
Ready to submit your research? Choose BMC and benefit from:

- fast, convenient online submission

- thorough peer review by experienced researchers in your field

- rapid publication on acceptance

- support for research data, including large and complex data types

- gold Open Access which fosters wider collaboration and increased citations

- maximum visibility for your research: over $100 \mathrm{M}$ website views per year

At BMC, research is always in progress.

Learn more biomedcentral.com/submissions 